medRxiv preprint doi: https://doi.org/10.1101/2020.09.23.20187450; this version posted September 24, 2020. The copyright holder for this preprint (which was not certified by peer review) is the author/funder, who has granted medRxiv a license to display the preprint in perpetuity. This article is a US Government work. It is not subject to copyright under 17 USC 105 and is also made available for use under a CCO license.

Preclinical WM microstructural decline

\title{
Accelerated decline in white matter microstructure in subsequently impaired older adults and its relationship with cognitive decline.
}

Owen A. Williams ${ }^{1,2^{*}}$, Andrea T. Shafer ${ }^{1 *}$, Evian Perez Rivera ${ }^{3}$, Yang An ${ }^{1}$, Bennett A. Landman ${ }^{4}$, Luigi Ferrucci ${ }^{5}$, Susan M. Resnick ${ }^{1}$

${ }^{1}$ Laboratory of Behavioral Neuroscience, National Institute on Aging, Baltimore, Maryland 21224, USA

${ }^{2}$ Department of Experimental Psychology, University of Oxford, Oxford, United Kingdom

${ }^{3}$ San Juan Bautista School of Medicine, Caguas, PR

${ }^{4}$ School of Engineering, Vanderbilt University, Nashville, TN

${ }^{5}$ Longitudinal Studies Section, Translational Gerontology Branch, National Institute on Aging, Baltimore, Maryland 21224, USA

*Joint First Authors

\begin{abstract}
INTRODUCTION: Little is known about longitudinal decline in white matter (WM) microstructure and its associations with cognition in preclinical Alzheimer's disease (AD).
\end{abstract}

METHODS: Longitudinal diffusion tensor imaging and neuropsychological testing from 50 older adults who subsequently developed mild cognitive impairment or dementia (subsequently impaired, SI) and 200 cognitively normal controls. Rates of WM decline were compared between groups using voxel-wise linear mixed-effects models. Associations between change in WM and cognition were examined.

RESULTS: SI had faster decline in fractional anisotropy (FA) in the right inferior frontooccipital fasciculus (R.IFOF) and bilateral splenium of the corpus callosum. Decline in R.IFOF FA was related to decline in verbal memory, visuospatial ability, processing speed, and MMSE $(p \leq 0.05)$. Decline in bilateral splenium FA was related to decline in verbal fluency, processing speed, and MMSE ( $\mathrm{p} \leq$ 0.05).

DISCUSSION: Accelerated regional WM decline is characteristic of preclinical AD and related to domain specific cognitive decline.

Key Words: Diffusion tensor imaging; preclinical Alzheimer's disease; longitudinal change; white matter microstructure; cognition.

\section{Introduction}

Dementia is one of the leading causes of death and disability worldwide, and it is projected to affect over 151 million individuals by 2050 [1]. Alzheimer's disease (AD) is the most common cause of dementia. AD is a progressive neurodegenerative disease with a long preclinical phase typically defined by the accumulation of beta amyloid $(\mathrm{A} \beta)$ and phosphorylated tau with subsequent 
medRxiv preprint doi: https://doi.org/10.1101/2020.09.23.20187450; this version posted September 24, 2020. The copyright holder for this preprint (which was not certified by peer review) is the author/funder, who has granted medRxiv a license to display the preprint in perpetuity. This article is a US Government work. It is not subject to copyright under 17 USC 105 and is also made available for use under a CCO license.

Preclinical WM microstructural decline

acceleration of regional brain atrophy in the absence of clinical symptoms [2-5]. However, the nature of longitudinal changes in white matter (WM) microstructure in the preclinical phase of AD has been less well characterized.

Anti-amyloid clinical trials have failed to show that removal of $A \beta$ is associated with improved cognitive outcomes [6]. It has been proposed that trials are not targeting the disease early enough $[6,7]$. This has led to an increased focus on the asymptomatic preclinical stage of $\mathrm{AD}$, with the hope that interventions administered before neuronal damage and symptom onset may be more effective $[8,9]$. For such a strategy to be successful, sensitive biomarkers must be developed that can accurately detect signs of preclinical AD changes and provide surrogate markers of disease progression to assess the efficacy of disease-modifying treatments [10]. Thus, it is critical to define the earliest, and possibly subtle, changes in brain structure in preclinical $\mathrm{AD}$ to identify all viable biomarkers for AD.

Network-based theories of AD point to patterns of disconnection of spatially dispersed but functionally connected regions of the brain, e.g. the default mode network (DMN) $[11,12]$. Functional networks are supported by the cerebral WM connecting the gray matter regions implicated in $\mathrm{AD}$. It is therefore important to understand the spatial pattern of structural alterations of WM in the preclinical stages of AD. Diffusion tensor imaging (DTI) is an imaging technique that is sensitive to the microstructural properties of cerebral WM [13]. In the WM, axons, myelin sheaths and neurofilaments restrict both direction and magnitude of Brownian diffusion, leading to highly directional diffusion running in parallel with WM tracts. Fractional anisotropy (FA) is used to quantify the degree of anisotropic diffusion and mean diffusivity (MD) is used to quantify the magnitude of total water diffusion within brain tissue. Age-related decreases in FA and increases in MD have been widely reported from both cross-sectional and longitudinal studies and are thought to reflect microstructural damage that is associated with cognitive decline [14-18]. However, while preclinical $\mathrm{AD}$ is associated with declines in several cognitive domains including episodic memory, executive functioning, visuospatial functioning and processing speed [19, 20], few studies have examined the associations between changes in DTI metrics and changes in cognition in preclinical AD [21].

Compromised WM microstructure (lower FA, higher $\mathrm{MD}$ ) in $\mathrm{AD}$ compared to cognitively normal (CN) controls has been reported in diffuse areas including the fornix, splenium of the corpus callosum, inferior fronto-occipital fasciculus, and uncinate fasciculus.[22-24] However, studies of alterations in WM microstructure during the preclinical phase have been less consistent. For example, in samples of individuals with autosomal dominant forms of early onset AD (EOAD), different regional findings or lack of associations have been reported across studies. In one study [25], FA was reduced in the fornix and orbitofrontal WM in preclinical EOAD patients compared with non-gene carrier relatives. However, other studies found no significant differences in DTI metrics between preclinical EOAD participants and non-carrier relatives [26, 27]. These studies all tend to have small samples of preclinical EOAD patients (typically less than 30) and are limited to crosssectional analyses that do not assess withinindividual changes in WM microstructure. Furthermore, EOAD represents a small percentage of cases of $\mathrm{AD}$, and additional studies focusing on preclinical stages in late onset $\mathrm{AD}$ are needed.

The aim of the current study was to characterize the course of microstructural WM changes in preclinical $\mathrm{AD}$ and to interrogate their relationship with cognitive decline. To elucidate AD-related regional changes in WM microstructure prior to symptom onset, we 
medRxiv preprint doi: https://doi.org/10.1101/2020.09.23.20187450; this version posted September 24, 2020. The copyright holder for this preprint (which was not certified by peer review) is the author/funder, who has granted medRxiv a license to display the preprint in perpetuity. This article is a US Government work. It is not subject to copyright under 17 USC 105 and is also made available for use under a CCO license.

Preclinical WM microstructural decline

Table 1. Participant characteristics stratified by cognitive groups

\begin{tabular}{lccc}
\hline & Cognitively Normal & $\begin{array}{c}\text { Subsequently } \\
\text { Impaired }\end{array}$ & p-value \\
\hline $\mathrm{N}$ & 200 & 50 & - \\
Age, mean (SD) & $80.68(5.30)$ & $81.90(6.26)$ & 0.163 \\
Sex (males \%) & $113(56.5)$ & $31(62.0)$ & 0.587 \\
Race (Whites \%) & $153(76.5)$ & $41(82.0)$ & 0.519 \\
Education, mean (SD) & $16.94(2.59)$ & $17.10(2.96)$ & 0.728 \\
APOE \&4 (\%) [\# missing] & $37(18.9)[4]$ & $10(20.8)[2]$ & 0.917 \\
Hypertension (\%) & $76(39.2)$ & $20(40.8)$ & 0.963 \\
Elevated Cholesterol (\%) & $57(28.5)$ & $13(27.1)$ & 0.986 \\
Diabetes (\%) & $14(7.3)$ & $4(8.7)$ & 0.494 \\
Obese (\%) & $30(15.0)$ & $5(10.0)$ & 0.494 \\
Has longitudinal DTI (\%) & $135(67.5)$ & $33(66.0)$ & 0.973 \\
Follow-up, mean (SD) & $3.38(1.51)$ & $3.05(1.32)$ & 0.381 \\
Time between last DTI and symptom onset, & - & $2.23(1.28)$ & - \\
yrs mean (SD) & &
\end{tabular}

*Number of participants with longitudinal data $(\mathrm{CN}=135, \mathrm{SI}=33)$

p-values obtained from t-tests for continuous variables and chi-square test for categorical variables

investigated voxel-wise differences in changes in FA and $\mathrm{MD}$ in individuals who later developed mild cognitive impairment (MCI) or $\mathrm{AD}$ versus those who remained $\mathrm{CN}$. We hypothesized that observed differences in rates of microstructural change would be identified in regions previously implicated in $\mathrm{AD}$ such as the cingulum, corpus callosum, and medial temporal lobe WM. Furthermore, we assessed the associations between localized rates of change in DTI metrics and rates of change in cognition in domains that show decline in AD.

\section{Materials and methods}

Participants

Participants were from the Baltimore Longitudinal Study of Aging (BLSA), a prospective study of physical and psychological aging that started in 1958 [28]. Participants were healthy at enrollment and those who were over time diagnosed with either MCI $(n=30)$ or dementia $(n=20)$ were matched using MatchIt [29] based on baseline age, sex, race, and follow-up time from first DTI in a 1:4 ratio with participants with normal cognitive status throughout follow-up. The
BLSA study is approved by the local Institutional Review Boards, and participants provided written informed consent at each visit. Determination of cognitive status was performed through established procedures, please refer to Supplementary Material (SM) for more information. Table 1 provides the sample characteristics for both cognitive status groups (50 subsequently impaired (SI) and 200 $\mathrm{CN}$ participants). For the SI group, the last DTI scan included in the analysis preceded the date of symptom onset. There were no significant differences between cognitive groups for any of the matching criteria including baseline age, sex, race, and length of follow-up from first 3T DTI scan. There were also no significant differences in years of education, apolipoprotein E $\varepsilon 4$ status, and vascular risk factors including hypertension, elevated cholesterol, diabetes mellitus, or obesity.

\section{DTI acquisition and preprocessing}

MRI data were acquired on three different 3 Tesla Philips Achieva scanners (scanners 1 and 2 at the Kennedy Krieger Institute and scanner 3 at the National Institute on Aging). The DTI acquisition protocols are provided in SM. A 
medRxiv preprint doi: https://doi.org/10.1101/2020.09.23.20187450; this version posted September 24, 2020. The copyright holder for this preprint (which was not certified by peer review) is the author/funder, who has granted medRxiv a license to display the preprint in perpetuity. This article is a US Government work. It is not subject to copyright under 17 USC 105 and is also made available for use under a CCO license.

Preclinical WM microstructural decline

general overview of the preprocessing steps is provided here, with more detailed information provided in SM. DTI data were corrected for physiological motion effects and eddy currents. Tensor fitting was carried out using FSL FDT using the ordinary least squares method. Resultant FA and MD maps were selected for analysis. Quality control methods for DTI data in the BLSA have been described previously[30, 31]. Baseline motion and motion over time did not differ between groups, see SM.

The tract-based spatial statistics (TBSS [32]) analysis utilized a BLSA-specific FA template was generated from FA images from 60 (30 men, 30 women) cognitively normal BLSA participants with a mean age of 69.9 years (range 60-80 years) using advanced normalization tools (ANTS) MultivariateTemplateConstruction2 [33]. TBSS was used to generate a WM skeleton to facilitate voxel-wise analysis in WM tracts common to all participants. See SM for details of the processing pipeline.

\section{Cognitive measures and domains}

Composite scores were calculated for verbal memory, executive function, attention, visuospatial ability, verbal fluency, and processing speed. The BLSA neuropsychological test battery has been described previously [31, 34] and details are provided in SM, Table S1. We also examined performance on a measure of mental status, the mini-mental state examination (MMSE) [35].

Statistical analyses

Differences in longitudinal WM microstructural trajectories due to subsequent impairment

Voxel-wise analysis was performed in MATLAB (Natick, Massachusetts: The MathWorks Inc.). To estimate group differences in longitudinal change in WM microstructure, linear mixed-effects models were implemented using fitlme (https://www.mathworks.com/help/stats/fitlme .html) with FA or MD as the dependent variable. The analysis was restricted to voxels in the mean FA skeleton image. Intercept and time (follow-up time in years from first 3T DTI scan) were entered as random effects with unstructured covariance. Fixed effects included cognitive group (SI/preclinical $=1$, cognitively stable $=0)$, baseline age (mean centered), sex, race, scanner, baseline motion (mean FD), and 2-way interactions of cognitive group, baseline age, sex, and race with time. To control for the effect of multiple comparisons, contrasts of interest (the main effect of cognitive group and cognitive group*time interaction) were examined using a p-value of less than 0.005 and cluster size of 30 voxels or more and also using a more conservative approach, false discovery rate (FDR) [36]. For each cluster that met these requirements, the coordinates of the peak voxel (defined as highest t-value) were used to define the location of the cluster by comparison with the Johns Hopkins University ICBM-DTI-81 WM labels atlas [37]. While the primary focus of this study was to assess group differences in longitudinal change in DTI metrics, we also report baseline results in SM.

\section{Relationship between change in FA and change in cognition}

We first used linear mixed models to examine cognitive change in the SI relative to $\mathrm{CN}$ groups in this subsample with concurrent cognitive and DTI data. The same linear mixed-effects models were used to estimate group differences in longitudinal change as were used for the DTI data minus the fixed effect for scanner ( $\mathrm{R}$ 3.3.2, nlme 3.1-139). Next, we assessed the amount of betweenperson variability in preclinical longitudinal change explained by the effect of interest (subsequent cognitive group) for each outcome (cognition and DTI). The amount of variance explained $\left(R^{2}\right)$ in the change trajectory accounted for by cognitive group is a measure 
medRxiv preprint doi: https://doi.org/10.1101/2020.09.23.20187450; this version posted September 24, 2020. The copyright holder for this preprint (which was not certified by peer review) is the author/funder, who has granted medRxiv a license to display the preprint in perpetuity. This article is a US Government work. It is not subject to copyright under 17 USC 105 and is also made available for use under a CCO license.

Preclinical WM microstructural decline

Table 2. White matter clusters showing differences in the rates of change in FA and MD between SI and $\mathrm{CN}$ groups. The peak $\mathrm{t}$-value is reported for each cluster.

\begin{tabular}{lcccccc}
\hline FA & Voxels & t-value & X & Y & Z & FDR* \\
\hline Splenium Corpus Callosum (R) & $728^{\dagger}$ & -5.34 & 21 & -49 & 13 & $124,107,67$ \\
Splenium Corpus Callosum (L) & $570^{\dagger}$ & -5.69 & -24 & -58 & 14 & $118,58,53$ \\
Inferior Fronto-occipital fasciculus (R) & $161^{\dagger}$ & -5.77 & 25 & 20 & -7 & 42 \\
Superior Cerebellar peduncle (L) & 55 & -4.87 & -7 & -40 & -26 & \\
Postcentral gyrus WM (R) & 48 & -4.60 & 30 & -18 & 48 & \\
Postcentral gyrus WM (L) & 47 & -4.14 & -24 & -22 & 50 & \\
Middle/lateral occipital gyrus WM (L) & 37 & -4.44 & -29 & -79 & -2 & \\
Cingulate gyrus WM (L) & 31 & -5.45 & -10 & -49 & 19 & \\
Genu Corpus Callosum (L) & 31 & -4.63 & -9 & 31 & -3 & \\
Posterior Corona radiata (R) & 30 & -5.34 & 20 & -52 & 27 & \\
\hline MD & Voxels & t-value & X & Y & Z & FDR* \\
\hline Splenium Corpus Callosum (R) & 260 & 5.31 & 17 & -45 & 15 & \\
Splenium Corpus Callosum (L) & 133 & 4.36 & -15 & -44 & 23 & \\
Postcentral gyrus WM (R) & 53 & 5.52 & 30 & -17 & 46 & \\
Splenium Corpus Callosum (L) & 43 & 4.62 & -7 & -34 & 25 & \\
Posterior thalamic radiation (L) & 38 & 4.40 & -28 & -60 & 14 & \\
Posterior thalamic radiation (R) & 38 & -3.71 & 34 & -36 & 14 & \\
Splenium Corpus Callosum (R) & 35 & 3.57 & 15 & -36 & 29 & \\
Cerebellar WM (R) & 32 & -3.55 & 23 & -64 & -48 & \\
\hline
\end{tabular}

*Effects that survived FDR correction were split into smaller clusters. Values represent number of voxels in FDR clusters. Peak coordinates are from the BLSA FA template affine aligned to MNI space.

${ }^{\dagger}$ Clusters extracted for brain-behavior correlations.

Abbreviations: FA, fractional anisotropy; $\mathrm{MD}$, mean diffusivity; $\mathrm{R}=\mathrm{Right}, \mathrm{L}=\mathrm{Left}, \mathrm{FDR}=\mathrm{False}$ discovery rate correction. SI, subsequently impaired; CN cognitively normal

of effect-size used in multilevel models [38, 39] and can provide an estimate of how sensitive the outcome is in detecting differences in change over time due to preclinical disease, see SM for additional information.

Next, we examined the relationship between change in FA and change in cognition, focusing on the three larger uncorrected FA clusters that survived FDR. Partial correlations between estimated slopes controlling for age, sex, and race were used to assess the relationship between change in mean FA and change in cognition, see SM for more information.

\section{Results}

Faster rates of WM microstructural change in the splenium and inferior fronto-occipital fasciculus in those with subsequent impairment

Results from the LME models for the cognitive group*time interaction revealed 10 clusters where FA declined at faster rates in the SI group compared to the $\mathrm{CN}$ group over time (Table 2). The largest areas of decline were in the splenium of the corpus callosum and in the inferior fronto-occipital fasciculus, see Figure 2. Clusters in these areas survived FDR correction for multiple comparisons, but this correction resulted in smaller, separate clusters. For example, the largest cluster (right splenium of the corpus callosum, 728 voxels) became three smaller clusters of 124 voxels, 107 voxels and 67 voxels (Table 2). Other areas showing 
medRxiv preprint doi: https://doi.org/10.1101/2020.09.23.20187450; this version posted September 24, 2020. The copyright holder for this preprint (which was not certified by peer review) is the author/funder, who has granted medRxiv a license to display the preprint in perpetuity. This article is a US Government work. It is not subject to copyright under 17 USC 105 and is also made available for use under a CCO license.

Preclinical WM microstructural decline
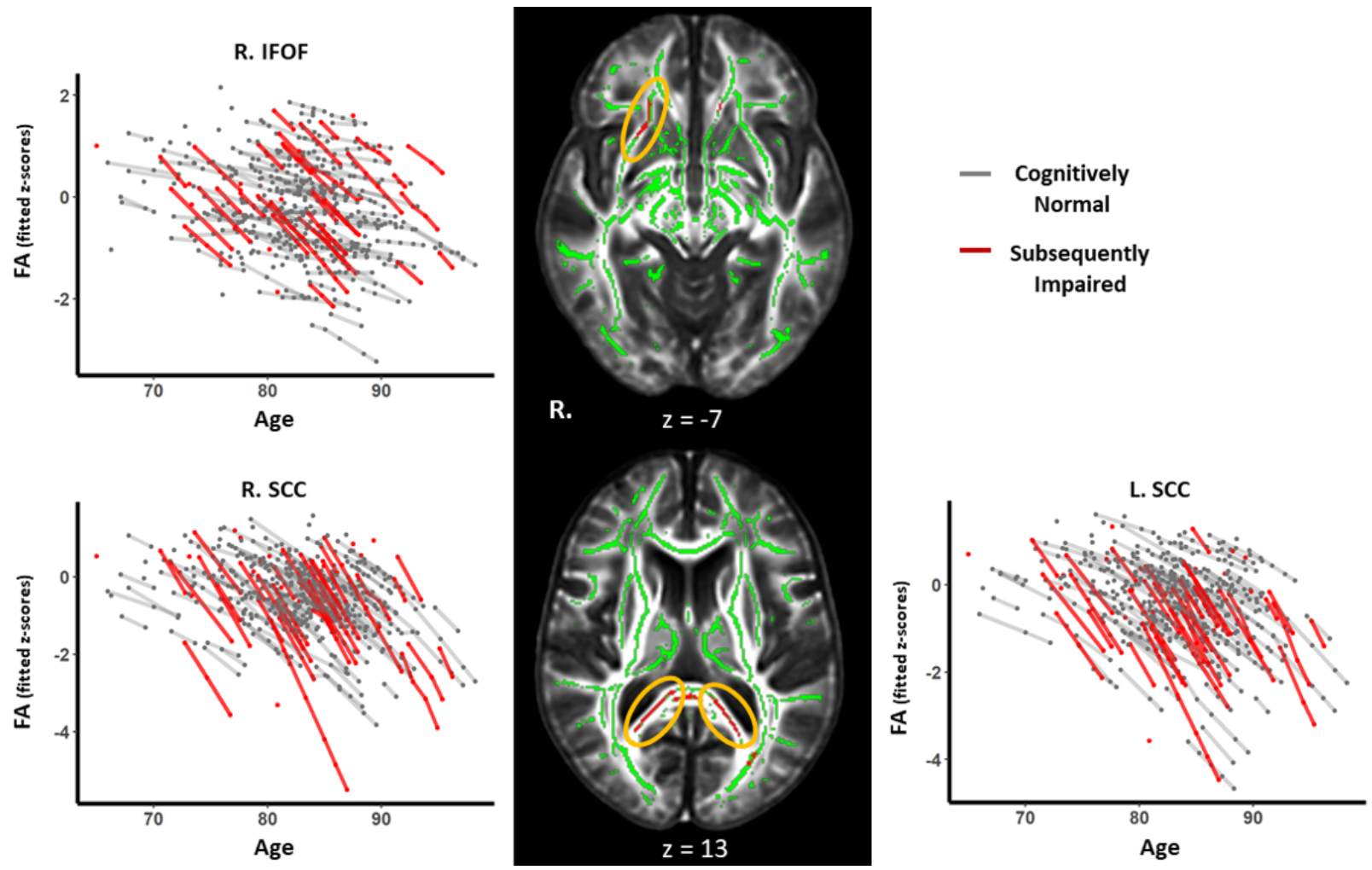

Figure 1. White matter clusters showing accelerated microstructural decline in the SI group. Line graphs show modelled trajectories of decline in FA for clusters in the right inferior fronto-occipital fasciculus, right splenium of the corpus callosum, and left splenium of the corpus callosum. The black panel shows axial slices where clusters with accelerated FA decline were found for the SI group in the right inferior frontooccipital fasciculus (top) and bilateral splenium of the corpus callosum (bottom) highlighted in red and indicated by the yellow ellipsoids.

faster declines in FA were the superior cerebellar peduncle, postcentral gyrus WM, middle/lateral occipital gyrus WM, cingulate gyrus WM, genu of the corpus callosum, and posterior corona radiata. However, these clusters did not survive FDR correction.

Six clusters were found to show faster increases in MD over time for the SI relative to the CN group and two clusters showed faster increases in MD in the CN vs. SI group (Table 2). Of the six clusters showing faster increase in MD for the SI group, four were in the splenium of the corpus callosum and the remaining two clusters were in the $R$. postcentral gyrus and L. posterior thalamic radiation. The two clusters with slower increases in $\mathrm{MD}$ in the SI compared to the $\mathrm{CN}$ group were in the $\mathrm{R}$. posterior thalamic radiation and $\mathrm{R}$. cerebellar WM. None of the clusters showing longitudinal change in MD survived FDR correction.

Correlations between change in FA and change in cognition

Linear mixed-effects models controlling for age, sex, and race were performed to cognitively characterize this DTI subsample of the BLSA. Significantly faster rates of cognitive decline in SI compared with $\mathrm{CN}$ participants were observed for memory, executive function, and processing speed (see Table 3 and Supplementary Material, Figure S1), but not for spatial ability or attention. Effect sizes for the group differences in rates of 
medRxiv preprint doi: https://doi.org/10.1101/2020.09.23.20187450; this version posted September 24, 2020. The copyright holder for this preprint (which was not certified by peer review) is the author/funder, who has granted medRxiv a license to display the preprint in perpetuity. This article is a US Government work. It is not subject to copyright under 17 USC 105 and is also made available for use under a CCO license.

Preclinical WM microstructural decline

longitudinal change were estimated using an $R^{2}$ statistic for multilevel models in which the amount of residual variance in between-person slopes captured by cognitive status was calculated for cognitive and DTI measures. These showed that the cognitive status grouping explained more between-person variation in the longitudinal trajectories of FA
(L.SCC, 76\%; R. SCC, 81\%; R. IFOF, 61\%) when compared to the longitudinal trajectories of the cognitive measures. Within the cognitive domains examined, longitudinal trajectories for processing speed $(42 \%)$ and memory $(25 \%)$ were the most sensitive to subsequent cognitive status, see Table 3.

Table 3. Differences between SI and CN groups in longitudinal rates of change in cognition and the three main FA clusters showing differences. The linear mixed-effects model controlled for inter-individual differences in age, sex, and race. The results reported below for the FA clusters were derived from z-scored, baseline anchored mean raw FA values extracted from the clusters. Here, the models are identical for the cognitive and FA data. Effect size for differences in longitudinal trajectories between SI and CN groups was determined using a $R^{2}$ statistic for multilevel models in which the residual variance in between-person slopes captured by including the effect of subsequent impairment was estimated.

\begin{tabular}{lccc}
\hline Cognitive Domain & Beta & P-value & Effect Size \\
\hline Verbal Memory & $\mathbf{- 0 . 0 7 5 *}$ & $\mathbf{0 . 0 4 4}$ & 24.93 \\
Executive Function & $\mathbf{- 0 . 0 8 1 *}$ & $\mathbf{0 . 0 3 9}$ & 18.53 \\
Attention & -0.059 & 0.079 & 7.21 \\
Verbal Fluency & -0.056 & 0.079 & 11.06 \\
Visuospatial Ability & -0.02 & 0.530 & -11.06 \\
Processing Speed & $\mathbf{0 . 1 1 9} \dagger$ & $<\mathbf{0 . 0 0 1}$ & 41.73 \\
MMSE & -.099 & 0.096 & 18.86 \\
\hline WM ROI $^{+}$ & $\mathbf{B e t a}$ & P-value & \\
\hline Right SCC & $\mathbf{- 0 . 2 8 4 \dagger}$ & $<\mathbf{0 . 0 0 1}$ & 75.59 \\
Left SCC & $\mathbf{- 0 . 2 5 4 \dagger}$ & $<\mathbf{0 . 0 0 1}$ & 60.78 \\
Right IFOF & $\mathbf{- 0 . 1 7 5 \dagger}$ & $<\mathbf{0 . 0 0 1}$ & \\
\hline
\end{tabular}

* significant at $\mathrm{p} \leq 0.05$.

$\uparrow$ significant at $\mathrm{p} \leq 0.01$.

${ }^{+}$All datapoints (subjects and visits) were utilized for the WM ROIs, however, similar results were obtained in analyses based on matched sample sizes between models.

Abbreviations: MMSE, mini-mental state examination; SCC, splenium of corpus callosum; IFOF, Inferior fronto-occipital fasciculus; SI, subsequently impaired; CN cognitively normal.

For the three cognitive domains that showed significantly faster decline in SI participants (processing speed, memory, and executive function), decline in processing speed was associated with decline in FA across all three regions showing greater FA decreases in the SI group (L. SCC, $\rho=0.169, \mathrm{p}=0.034$; R. SCC, $\rho=0.180, p=0.023$; R. IFOF, $\rho=0.265, p=$
0.001, see Figure 3A). Decline in episodic memory was associated with FA decline in the right IFOF $(\rho=0.182, p=0.020$, see Figure $3 \mathrm{~B})$, whereas no associations were found between decline in executive function and FA in the clusters examined, see Table 4. Of the cognitive domains and MMSE that did not show significantly faster decline for SI 
medRxiv preprint doi: https://doi.org/10.1101/2020.09.23.20187450; this version posted September 24, 2020. The copyright holder for this preprint (which was not certified by peer review) is the author/funder, who has granted medRxiv a license to display the preprint in perpetuity. This article is a US Government work. It is not subject to copyright under 17 USC 105 and is also made available for use under a CCO license.

\section{Preclinical WM microstructural decline}

participants, decline in MMSE was linked to decline in FA in all clusters, see Figure $3 \mathrm{C}$ and Table 4. Decline in verbal fluency was associated with FA decline in bilateral SCC and decline in visuospatial ability with FA decline in the R. IFOF.

Table 4. Associations between change in FA and change in cognition. Associations were determined by partial correlations controlling for age, sex, and race. Partial correlations were performed between slopes for subjects with longitudinal data.

\begin{tabular}{cccccccrrr}
\hline & \multicolumn{3}{c}{ Left Splenium CC } & \multicolumn{3}{c}{ Right Splenium CC } & \multicolumn{2}{c}{ Right IFOF } \\
\hline & Pearson's r & P-value & $95 \%$ CI & Pearson's r & P-value & $95 \%$ CI & Pearson's r & P-value & $95 \%$ CI \\
\hline VM & 0.106 & 0.183 & $-0.05,0.26$ & 0.126 & 0.111 & $-0.03,0.28$ & $\mathbf{0 . 1 8 2}$ & $\mathbf{0 . 0 2 1 *}$ \\
EF & 0.043 & 0.606 & $-0.12,0.19$ & -0.038 & 0.649 & $-0.2,0.11$ & 0.045 & 0.590 & $-0.12,0.2$ \\
ATT & -0.002 & 0.98 & $-0.16,0.15$ & 0.01 & 0.87 & $-0.14,0.17$ & -0.05 & 0.52 & $-0.2,0.1$ \\
VF & $\mathbf{0 . 1 9}$ & $\mathbf{0 . 0 2 *}$ & $\mathbf{0 . 0 4 , 0 . 3 3}$ & $\mathbf{0 . 2 3}$ & $\mathbf{0 . 0 0 3 *}$ & $\mathbf{0 . 0 8 , 0 . 3 7}$ & 0.05 & 0.52 & $-0.1,0.2$ \\
VSA & 0.069 & 0.386 & $-0.09,0.22$ & -0.01 & 0.9 & $-0.16,0.15$ & $\mathbf{0 . 1 8 4}$ & $\mathbf{0 . 0 1 9 *}$ & $\mathbf{0 . 0 3 , 0 . 3 3}$ \\
PS & $\mathbf{0 . 1 6 7}$ & $\mathbf{0 . 0 3 8 *}$ & $\mathbf{0 . 0 1 , 0 . 3 2}$ & $\mathbf{0 . 1 7 9}$ & $\mathbf{0 . 0 2 5 *}$ & $\mathbf{0 . 0 3 , 0 . 3 3}$ & $\mathbf{0 . 2 6 6}$ & $\mathbf{0 . 0 0 5 * *}$ & $\mathbf{0 . 1 1 , 0 . 4}$ \\
MMSE & $\mathbf{0 . 1 6}$ & $\mathbf{0 . 0 5 *}$ & $\mathbf{0 . 0 0 3 , 0 . 3}$ & $\mathbf{0 . 1 8 5}$ & $\mathbf{0 . 0 2 *}$ & $\mathbf{0 . 0 3 , 0 . 3 3}$ & $\mathbf{0 . 2 3}$ & $\mathbf{0 . 0 0 4 *}$ & $\mathbf{0 . 0 8 , 0 . 3 7}$ \\
\hline
\end{tabular}

* significant at $\mathrm{p} \leq 0.05$.

$* *$ significant at $\mathrm{p} \leq 0.01$.

Abbreviations: VM, verbal memory; EF, executive function; ATT, attention; VF, verbal fluency; VSA, visuospatial ability; PS, processing speed; SCC, splenium of corpus callosum; IFOF, Inferior fronto-occipital fasciculus. 
medRxiv preprint doi: https://doi.org/10.1101/2020.09.23.20187450; this version posted September 24, 2020. The copyright holder for this preprint (which was not certified by peer review) is the author/funder, who has granted medRxiv a license to display the preprint in perpetuity. This article is a US Government work. It is not subject to copyright under 17 USC 105 and is also made available for use under a CCO license.

Preclinical WM microstructural decline

A. Processing Speed

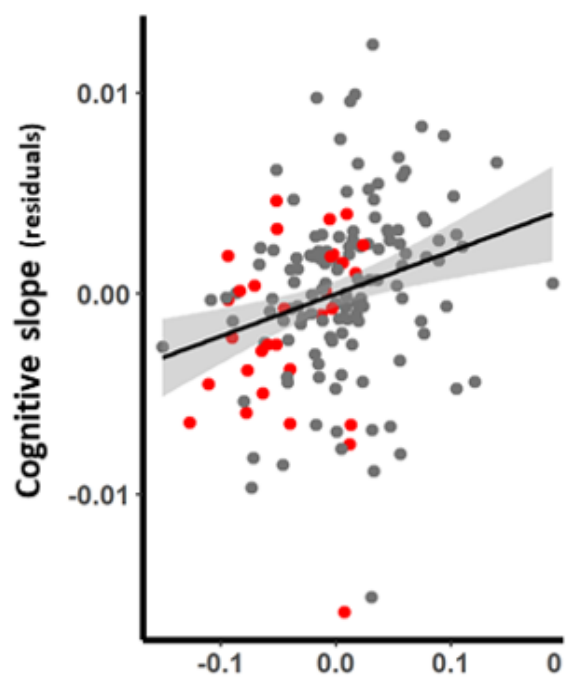

B. Verbal Memory

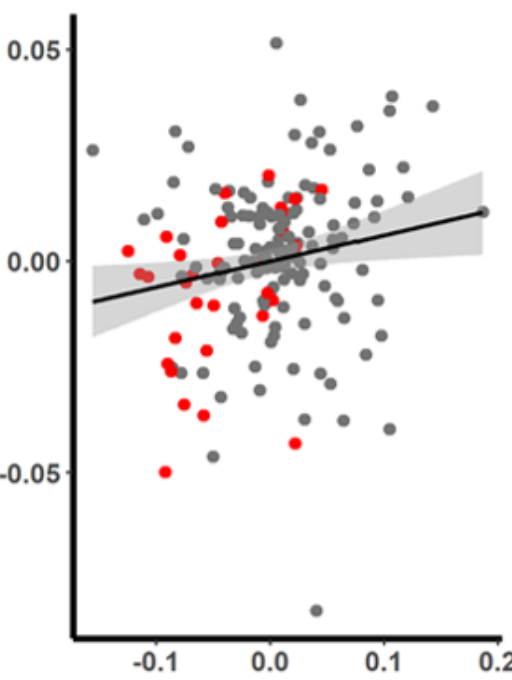

R. IFOF slope (residuals)

\section{MMSE}

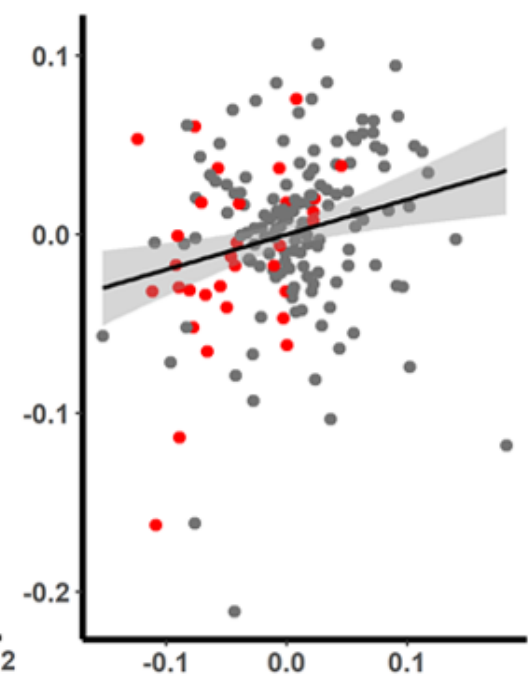

Cognitively Normal

Subsequently Impaired

Figure 2. Associations bewteen change in FA and change in cognition. Figure shows the relationship between the rate of change in the right inferior fronto-occipital fasciculus and the rate of change in processing speed (panel A), verbal memory (panel B), and MMSE (panel C). The effects of age, sex, and race were removed from the estimated slopes for FA and cognition. Shaded areas indicate $95 \%$ confidience intervals.

\section{Discussion}

Using a case-control subset of the BLSA, we found that faster rates of WM microstructural degeneration are detectable before clinical symptoms of MCI or AD are apparent. Longitudinal voxel-wise analyses identified several clusters (bilateral splenium of corpus callosum and right inferior frontooccipital fasciculus) where FA declined faster in a sample of subsequently impaired individuals compared to a control group who remained $\mathrm{CN}$. While several overlapping clusters were found where MD was increasing faster in the SI group compared to controls, these clusters did not remain significant after FDR correction. Furthermore, rates of decline in WM microstructure were associated with rates of decline in cognition in domains that did and did not show significant differences in rates of decline in cognitive status groups.

The largest clusters to show faster decline in FA in the SI compared to $\mathrm{CN}$ group, and survive FDR correction, were in the left and right splenium of the corpus callosum. This bilateral pattern of accelerated change suggests that the splenium may be susceptible to microstructural decline in individuals on a trajectory towards MCI/AD. Our results extend prior reports of atrophy and reduced microstructure of the splenium of the corpus callosum in $\mathrm{MCI} / \mathrm{AD}$ participants compared to $\mathrm{CN}$ participants [40] and in at risk APOE e4 carriers who show faster decline in FA in this area.[31] Here we have shown that such changes can be detected in the preclinical stages, before onset of clinical symptoms. The third largest cluster was in the inferior fronto-occipital 
medRxiv preprint doi: https://doi.org/10.1101/2020.09.23.20187450; this version posted September 24, 2020. The copyright holder for this preprint (which was not certified by peer review) is the author/funder, who has granted medRxiv a license to display the preprint in perpetuity. This article is a US Government work. It is not subject to copyright under 17 USC 105 and is also made available for use under a CCO license.

Preclinical WM microstructural decline

fasciculus. The microstructure of the IFOF has been shown to decline faster in AD patients compared to $\mathrm{CN}$ controls [23] and show cross-sectional differences in DTI metrics between preclinical EOAD participants and controls. [25]. The splenium of the corpus callosum contains commissural fibers that connect association regions in the temporal and parietal lobes, including the precuneus[41], while the IFOF contains fibers connecting frontal and occipital lobes. Evidence suggests that the precuneus and frontal lobe areas are among the earliest regions to accumulate $A \beta$.[42] Therefore it is possible the microstructural decline is related to pathological changes occurring in these regions early in the preclinical stage of $\mathrm{AD}$.

We found no evidence of faster microstructural decline in limbic structures, including the fornix. This contrasts with Ringman et al. [25] who found crosssectional evidence of lower FA in the fornix in comparing preclinical EOAD to non-gene carrier family members. This difference may be due to Ringman et al.'s use of small ROIs (two voxels) placed in each subject's native space FA maps rather than a TBSS approach. In another cross-sectional study of preclinical EOAD participants compared to $\mathrm{CN}$ controls using TBSS, no difference in DTI markers in the fornix was reported. [43]

Cognitively characterizing this DTI subsample of the BLSA confirmed that the SI group had similar preclinical cognitive profiles to other preclinical samples [19, 44]. Cognitive trajectories for three domains (verbal memory, executive function, and processing speed) showed faster decline in the SI group. The pattern for all cognitive outcomes examined, apart from visuospatial ability, was similar with trends toward greater decline the SI group. The exception of visuospatial ability is interesting as our recent publication of change-points in $\mathrm{AD}$ in a larger BLSA preclinical sample found the earliest change-point in cognition for these participants was visuospatial ability [20]. It is possible that the relatively short follow-up in the current sample limited our ability to detect group differences. Furthermore, the inclusion of individuals with MCI in the SI sample in the present study was necessary to increase sample size due to the more recent introduction of DTI. The heterogeneity in the SI sample due to the inclusion of both MCI and $\mathrm{AD}$ endpoints, and heterogeneity in cognitive trajectories, may explain the lack of significant differences in visuospatial trajectories over time in this BLSA subsample.

Comparing the effect size $\left(R^{2}\right)$ for group membership (proportion of explained variance in rates of change by group membership), we found FA to yield considerably higher values compared to the cognitive outcomes. These findings are not surprising as the cognitive data are more variable over time due to a greater number of factors influencing performance. However, these findings suggest that regional changes over time in DTI markers may provide a more robust marker of changes during preclinical AD.

Associations between change in FA and change in cognition were observed for five domains. Of the three domains that showed significant differences in decline by group, faster decline in FA in the R IFOF was associated with the faster of decline in verbal memory, and faster decline in FA in all three clusters was related to faster decline in processing speed. Additionally, faster FA decline in all three clusters was related to MMSE, while the splenium clusters were linked to declines in verbal fluency and the $\mathrm{R}$ IFOF to visuospatial ability. These results extend previous findings that regional differences in frontal lobe WM microstructure between $\mathrm{AD}$ and controls was also correlated with memory performance.[44] While splenium FA decline was not related to verbal memory, it was related to verbal fluency, processing speed, and MMSE. These results are 
medRxiv preprint doi: https://doi.org/10.1101/2020.09.23.20187450; this version posted September 24, 2020. The copyright holder for this preprint (which was not certified by peer review) is the author/funder, who has granted medRxiv a license to display the preprint in perpetuity. This article is a US Government work. It is not subject to copyright under 17 USC 105 and is also made available for use under a CCO license.

Preclinical WM microstructural decline

consistent with a previous cross-sectional report showing $\mathrm{FA}$ in the splenium is associated with poorer cognition in $\mathrm{MCI} / \mathrm{AD}$ patients as measured by the clinical dementia rating scale.[45] The finding that processing speed was related to FA decline in all three clusters is perhaps less surprising given previous reports of significant associations between WM microstructure in these areas and processing speed in CN older adults.[46]

Results from this study should be considered in the context of several limitations. BLSA participants in this sample are highly educated, mostly white, and relatively old, with a mean baseline age of 80 years, which may limit generalizability. Furthermore, the follow-up period was relatively short, and while most participants had multiple DTI and cognitive assessments, some only contributed cross-sectional data. However, the sample size and longitudinal power are still improvements on previous studies of preclinical changes in DTI. The SI sample included participants, who were cognitively normal at the time of imaging but had research diagnoses of either MCI or AD as their final cognitive status at the time of analysis. While MCI is typically the prodromal stage of $\mathrm{AD}$ [47], it is possible that some of MCI participants will remain stable or develop non-AD pathologies. This heterogeneity may increase variance in the SI group, leading to an underestimation of the extent of localized WM microstructural damage in preclinical AD. Future work with larger samples of AD cases may address this issue. The study benefits from statistical matching of SI participants to $\mathrm{CN}$ participants with similar demographic features, allowing for higher confidence that the differences found between groups are indeed a result of the group differences in disease trajectories. However, we cannot exclude the possibility that some individuals in the $\mathrm{CN}$ group will develop cognitive impairment later, and it is possible that more robust differences may be found in samples where AD pathology is confirmed postmortem.

In this study, longitudinal DTI data were used to characterize voxel-wise patterns of accelerated decline in WM microstructure and its relationship to cognition during the preclinical phase of MCI/AD. Group membership explained more variance in rates of change in regional brain microstructure than it did in cognitive decline, suggesting DTI may be a powerful indicator of future risk of developing MCI/AD. In order to find the optimal imaging markers of preclinical $\mathrm{AD}$, future work should focus on elucidating the joint associations and temporal relationships between change in regional DTI metrics and changes in other markers of $\mathrm{AD}$ such as atrophy and $A \beta$ accumulation in the preclinical stage.

\section{Acknowledgements}

We thank the staff of the BLSA and the NIA 3T MRI facility for their assistance and the BLSA participants for their dedication to this study.

\section{Funding}

This research was supported by the Intramural Research Program of the National Institutes of Health, National Institute on Aging.

\section{Competing Interests}

Declaration of interests: None.

\section{References}

[1] Nitrini R, Bottino CM, Albala C, Capuñay NSC, Ketzoian C, Rodriguez JJL, et al. Prevalence of dementia in Latin America: a collaborative study of population-based cohorts. 2009;21:622-30.

[2] Armstrong NM, Huang C-W, Williams OA, Bilgel $M, A n Y$, Doshi J, et al. Sex differences in the association between amyloid and longitudinal brain volume change in cognitively normal older adults. Neurolmage: Clinical. 2019;22:101769. 
medRxiv preprint doi: https://doi.org/10.1101/2020.09.23.20187450; this version posted September 24, 2020. The copyright holder for this preprint (which was not certified by peer review) is the author/funder, who has granted medRxiv a license to display the preprint in perpetuity. This article is a US Government work. It is not subject to copyright under 17 USC 105 and is also made available for use under a CCO license.

Preclinical WM microstructural decline

[3] Jack Jr CR, Bennett DA, Blennow K, Carrillo $M C$, Dunn B, Haeberlein SB, et al. NIA-AA Research Framework: Toward a biological definition of Alzheimer's disease. Alzheimer's \& Dementia. 2018;14:535-62.

[4] Sperling RA, Aisen PS, Beckett LA, Bennett DA, Craft S, Fagan AM, et al. Toward defining the preclinical stages of Alzheimer's disease: Recommendations from the National Institute on Aging-Alzheimer's Association workgroups on diagnostic guidelines for Alzheimer's disease. Alzheimer's \& dementia. 2011;7:280-92.

[5] Villemagne $V L$, Burnham $S$, Bourgeat $P$, Brown B, Ellis KA, Salvado $O$, et al. Amyloid $\beta$ deposition, neurodegeneration, and cognitive decline in sporadic Alzheimer's disease: a prospective cohort study. The Lancet Neurology. 2013;12:357-67.

[6] van Dyck $\mathrm{CH}$. Anti-amyloid- $\beta$ monoclonal antibodies for Alzheimer's disease: pitfalls and promise. Biological psychiatry. 2018;83:311-9.

[7] Sarazin M, Dorothée G, de Souza LC, Aucouturier P. Immunotherapy in Alzheimer's disease: do we have all the pieces of the puzzle? Biological Psychiatry. 2013;74:329-32.

[8] Sevigny J, Chiao P, Bussière T, Weinreb PH, Williams $L$, Maier $M$, et al. The antibody aducanumab reduces $A \beta$ plaques in Alzheimer's disease. Nature. 2016;537:50.

[9] Sperling RA, Rentz DM, Johnson KA, Karlawish J, Donohue M, Salmon DP, et al. The A4 study: stopping $A D$ before symptoms begin? Science translational medicine. 2014;6:228fs13-fs13.

[10] Mak E, Gabel S, Mirette H, Su L, Williams GB, Waldman $A$, et al. Structural neuroimaging in preclinical dementia: from microstructural deficits and grey matter atrophy to macroscale connectomic changes. Ageing research reviews. 2017;35:250-64.

[11] Damoiseaux JS, Prater KE, Miller BL, Greicius MD. Functional connectivity tracks clinical deterioration in Alzheimer's disease. Neurobiology of aging. 2012;33:828. e19-. e30.

[12] Jones DT, Knopman DS, Gunter JL, GraffRadford J, Vemuri P, Boeve BF, et al. Cascading network failure across the Alzheimer's disease spectrum. Brain. 2016;139:547-62.
[13] Basser PJ, Mattiello J, LeBihan D. MR diffusion tensor spectroscopy and imaging. Biophysical journal. 1994;66:259-67.

[14] Barrick TR, Charlton RA, Clark CA, Markus HS. White matter structural decline in normal ageing: a prospective longitudinal study using tract-based spatial statistics. Neuroimage. 2010;51:565-77.

[15] Charlton RA, Schiavone F, Barrick T, Morris $\mathrm{R}$, Markus $H$. Diffusion tensor imaging detects age related white matter change over a 2 year follow-up which is associated with working memory decline. Journal of Neurology, Neurosurgery \& Psychiatry. 2010;81:13-9.

[16] Kennedy KM, Raz N. Aging white matter and cognition: differential effects of regional variations in diffusion properties on memory, executive functions, and speed. Neuropsychologia. 2009;47:916-27.

[17] Salat D, Tuch D, Greve D, Van Der Kouwe A, Hevelone N, Zaleta $A$, et al. Age-related alterations in white matter microstructure measured by diffusion tensor imaging. Neurobiology of aging. 2005;26:1215-27.

[18] Sexton CE, Walhovd KB, Storsve AB, Tamnes $C K$, Westlye LT, Johansen-Berg $H$, et al. Accelerated changes in white matter microstructure during aging: a longitudinal diffusion tensor imaging study. Journal of Neuroscience. 2014;34:15425-36.

[19] Bäckman L, Jones S, Berger A-K, Laukka EJ, Small BJ. Cognitive impairment in preclinical Alzheimer's disease: a meta-analysis. Neuropsychology. 2005;19:520.

[20] Williams OA, An Y, Armstrong NM, KitnerTriolo M, Ferrucci L, Resnick SM. Profiles of Cognitive Change in Preclinical and Prodromal Alzheimer's Disease Using Change-Point Analysis. Journal of Alzheimer's Disease. 2020;Preprint:1-12.

[21] Alm KH, Bakker A. Relationships Between Diffusion Tensor Imaging and Cerebrospinal Fluid Metrics in Early Stages of the Alzheimer's Disease Continuum. Journal of Alzheimer's Disease. 2019;70:965-81.

[22] Clerx L, Visser PJ, Verhey F, Aalten P. New MRI Markers for Alzheimer's Disease: A MetaAnalysis of Diffusion Tensor Imaging and a 
medRxiv preprint doi: https://doi.org/10.1101/2020.09.23.20187450; this version posted September 24, 2020. The copyright holder for this preprint (which was not certified by peer review) is the author/funder, who has granted medRxiv a license to display the preprint in perpetuity. This article is a US Government work. It is not subject to copyright under 17 USC 105 and is also made available for use under a CCO license.

Preclinical WM microstructural decline

Comparison with Medial Temporal Lobe Measurements. Journal of Alzheimer's Disease. 2012;29:405-29.

[23] Kitamura S, Kiuchi K, Taoka T, Hashimoto K, Ueda S, Yasuno F, et al. Longitudinal white matter changes in Alzheimer's disease: $A$ tractography-based analysis study. Brain Research. 2013;1515:12-8.

[24] Sexton CE, Kalu UG, Filippini N, Mackay CE, Ebmeier KP. A meta-analysis of diffusion tensor imaging in mild cognitive impairment and Alzheimer's disease. Neurobiology of Aging. 2011;32:2322.e5-.e18.

[25] Ringman JM, O'Neill J, Geschwind D, Medina L, Apostolova LG, Rodriguez $Y$, et al. Diffusion tensor imaging in preclinical and presymptomatic carriers of familial Alzheimer's disease mutations. Brain. 2007;130:1767-76.

[26] Parra MA, Saarimäki H, Bastin ME, Londono AC, Pettit L, Lopera F, et al. Memory binding and white matter integrity in familial Alzheimer's disease. Brain. 2015;138:1355-69.

[27] Sanchez-Valle R, Monte GC, Sala-Llonch R, Bosch B, Fortea J, Lladó $A$, et al. White matter abnormalities track disease progression in PSEN1 autosomal dominant Alzheimer's disease. Journal of Alzheimer's Disease. 2016;51:827-35. [28] Shock NW. Normal human aging: The Baltimore longitudinal study of aging. 1984.

[29] Ho DE, Imai K, King G, Stuart EA. Matching as nonparametric preprocessing for reducing model dependence in parametric causal inference. Political analysis. 2007;15:199-236.

[30] Lauzon CB, Asman AJ, Esparza ML, Burns SS, Fan $Q$, Gao $Y$, et al. Simultaneous analysis and quality assurance for diffusion tensor imaging. PLoS One. 2013;8:e61737.

[31] Williams OA, An Y, Beason-Held L, Huo Y, Ferrucci L, Landman BA, et al. Vascular burden and APOE $\varepsilon 4$ are associated with white matter microstructural decline in cognitively normal older adults. Neurolmage. 2019;188:572-83.

[32] Smith SM, Jenkinson M, Johansen-Berg $H$, Rueckert D, Nichols TE, Mackay CE, et al. Tractbased spatial statistics: voxelwise analysis of multi-subject diffusion data. Neuroimage. 2006;31:1487-505.
[33] Avants BB, Tustison NJ, Song G, Cook PA, Klein $A$, Gee JC. A reproducible evaluation of ANTs similarity metric performance in brain image registration. Neuroimage. 2011;54:203344.

[34] McCarrey AC, An Y, Kitner-Triolo $M H$, Ferrucci L, Resnick SM. Sex differences in cognitive trajectories in clinically normal older adults. Psychology and aging. 2016;31:166.

[35] Pezzotti P, Scalmana S, Mastromattei A, Di Lallo $D$. The accuracy of the MMSE in detecting cognitive impairment when administered by general practitioners: a prospective observational study. BMC Family Practice. 2008;9:29.

[36] Genovese CR, Lazar NA, Nichols T. Thresholding of statistical maps in functional neuroimaging using the false discovery rate. Neuroimage. 2002;15:870-8.

[37] Mori S, Oishi K, Jiang H, Jiang L, Li X, Akhter $K$, et al. Stereotaxic white matter atlas based on diffusion tensor imaging in an ICBM template. Neuroimage. 2008;40:570-82.

[38] Lorah J. Effect size measures for multilevel models: Definition, interpretation, and TIMSS example. Large-Scale Assessments in Education. 2018;6:8.

[39] Singer JD, Willett JB, Willett JB. Applied longitudinal data analysis: Modeling change and event occurrence: Oxford university press; 2003. [40] Di Paola M, Spalletta G, Caltagirone C. In vivo structural neuroanatomy of corpus callosum in Alzheimer's disease and mild cognitive impairment using different MRI techniques: a review. Journal of Alzheimer's disease. 2010;20:67-95.

[41] Hofer S, Frahm J. Topography of the human corpus callosum revisited-Comprehensive fiber tractography using diffusion tensor magnetic resonance imaging. Neurolmage. 2006;32:98994.

[42] Bilgel $M$, Prince JL, Wong DF, Resnick SM, Jedynak BM. A multivariate nonlinear mixed effects model for longitudinal image analysis: Application to amyloid imaging. Neurolmage. 2016;134:658-70.

[43] Li X, Westman E, Ståhlbom A, Thordardottir $\mathrm{S}$, Almkvist $\mathrm{O}$, Blennow $\mathrm{K}$, et al. White matter 
medRxiv preprint doi: https://doi.org/10.1101/2020.09.23.20187450; this version posted September 24, 2020. The copyright holder for this

preprint (which was not certified by peer review) is the author/funder, who has granted medRxiv a license to display the preprint in perpetuity.

This article is a US Government work. It is not subject to copyright under 17 USC 105 and is also made available for use under a CCO license.

Preclinical WM microstructural decline

changes in familial Alzheimer's disease. Journal of internal medicine. 2015;278:211-8.

[44] Huang J, Auchus AP. Diffusion tensor imaging of normal appearing white matter and its correlation with cognitive functioning in mild cognitive impairment and Alzheimer's disease. Annals of the New York Academy of Sciences. 2007;1097:259-64.

[45] Mielke MM, Kozauer N, Chan K, George M, Toroney J, Zerrate $\mathrm{M}$, et al. Regionally-specific diffusion tensor imaging in mild cognitive impairment and Alzheimer's disease. Neuroimage. 2009;46:47-55.

[46] Kerchner GA, Racine CA, Hale S, Wilheim R, Laluz $V$, Miller $B L$, et al. Cognitive processing speed in older adults: relationship with white matter integrity. PloS one. 2012;7.

[47] Jack Jr CR, Albert MS, Knopman DS, McKhann GM, Sperling RA, Carrillo MC, et al. Introduction to the recommendations from the National Institute on Aging-Alzheimer's Association workgroups on diagnostic guidelines for Alzheimer's disease. Alzheimer's \& dementia. 2011;7:257-62. 